\title{
The Thermodynamic Way of Assessing Reversible Metal Hydride Volume Expansion: Getting a Grip on Metal Hydride Formation Overpotential
}

Roland H. Pawelke

\begin{abstract}
The relative volume change of reversible metal hydrides upon hydrogenation is determined by means of the van't Hoff reaction entropy and STP ideal gas parameters. This method allows insight into the requirements to metal hydride formation, outlined by example of Ti$\mathrm{NaAlH}_{4}$. This work presents a timeless perspective on the sorbent phase thermodynamics of reversible chemical hydrogen storage systems.
\end{abstract}

\section{Introduction}

Reversible metal hydrides show upon hydrogenation a substantial volume change, e.g. up to about $+40 \%$ for $\mathrm{V} \rightarrow \mathrm{VH}_{2}{ }^{1}{ }^{1}$ which is an important safety aspect to consider in the design of metal hydride tanks. However, the powdery, transient nature of metal hydride beds makes the measurement of such expansion forces not trivial; ${ }^{2}$ compaction into pellets is not a remedy since the additional compression energy put into the material makes its presence forcibly felt once the system runs through sorption cycles hence it may even aggravate the issue. ${ }^{3,4}$ Calculations are a way out but these cannot be considered easy undertakings for a powder bed of transient properties. ${ }^{5,6}$ Thus, it is reasonable to ask for an alternate method of practical simplicity. Since the hydrogen sorption reactions are reversible processes of a thermodynamic two-phase gas-sorbent system, it must be possible to derive that information from the van't Hoff parameters.

\section{Methodical Approach}

The hydrogenation process is considered from a $p V$-energy balance point of view, comparing the metal and the metal hydride state of a system at IUPAC standard temperature and pressure (STP); the van't Hoff parameters $\Delta H$ and $\Delta S$ of the reaction have an implicit reference to $p^{\circ}=1$ bar. The hydrogenation process changes thus the density of the sorbent: $1 \mathrm{~g}$ of metal assume a certain volume $V$ (i.e. the density $\rho$ ), placing this gram-volume element in a hydrogen atmosphere at $\mathrm{p}^{\circ}$ results in the formation of the metal hydride while the chemical potential of the gas phase changes by $-\Delta H=\mu_{\mathrm{H} 2}$ and pressure above the sorbent drops to a fraction $x$ of $p^{\circ} .^{7}$ In order to re-establish a pressure of $p^{\circ}$ above the sorbent, the temperature $\Delta H / \Delta S=T_{1 \mathrm{bar}}$ is required. While the initial hydrogenation pressure $\mathrm{p}^{\circ}$ drops to a fraction $x$, the metal volume expands by $\Delta V$ and at the end of the absorption process, the chemical potentials of the gas and sorbent phase are on parity. Pressure is force per area and at thermodynamic equilibrium there must be force neutrality, thus the fraction $x$ of $p^{\circ}$ is a measure for the relative volume expansion $\Delta V_{\%}$ of a gram-volume element of hydrogen sorbent. The above basic process description is shown in equation 1a; equation $1 b$ expresses the same information by means of densities: index ${ }_{M}$ refers to the initial metal or sub-hydride state and index ${ }_{M H}$ to the final hydrogenated state.

$\rho_{M}=\frac{1 \mathrm{~g}}{V_{M}} \underset{1 \text { bar }}{\stackrel{\mathrm{H}_{2}}{\longrightarrow}} \frac{1 \mathrm{~g}}{\mathrm{p}^{\circ} V_{M}}=\frac{1 \mathrm{~g}}{x \mathrm{p}^{\circ} \Delta V_{\%}}$ 
$\frac{\rho_{M}}{\mathrm{p}^{\circ}}=\frac{\rho_{M}-\rho_{M H}}{x \mathrm{p}^{\circ}} \Rightarrow \frac{x \mathrm{p}^{\circ}}{\mathrm{p}^{\circ}}=x=1-\frac{\rho_{M H}}{\rho_{M}}=\Delta V_{\%}$

\section{Results}

Thus, the matter breaks down to identifying the fraction $x$ of $p^{\circ}$ at which the system settles in the hydrogenated state, approaching the issue via the ideal gas law is sensible. Advantageously simple in structure it nonetheless offers a good approximation for hydrogen behaviour at typical metal hydride reaction conditions ( $\mathrm{T}>300 \mathrm{~K}, \mathrm{p}<100 \mathrm{bar}$; the van der Waals ( $\mathrm{vdW}$ ) equation yields a $6.8 \%$ larger molar volume at 100 bar and $300 \mathrm{~K}$ ). Since $-\Delta H$ is equal to the excursion of the gas phase chemical potential from $\mu^{\circ},{ }^{7}$ it figures by amount to a $p V_{\mathrm{m}}$-energy term expressible via the ideal gas law as equation 2 shows.

$-\Delta H=\mu_{\mathrm{H} 2}=\left|p V_{\mathrm{m}}\right|=\mathrm{R} T$

Equations $3 a$ and $3 b$ show how relating equation 2 to the STP state by means of the ideal gas law yields the fraction $x$ of $\mathrm{p}^{\circ}$; the negative arithmetic sign in equation $3 \mathrm{~b}$ is for formal reasons as $\Delta S$ and $\Delta H$ are both negative for the hydrogenation reaction.

$\frac{\left|p V_{\mathrm{m}}\right|}{\mathrm{V}_{\mathrm{m}}^{\circ}}=\mathrm{p}^{\circ} \frac{T}{\mathrm{~T}^{\circ}} \quad$ I $\quad \Delta H / \Delta S=T_{1 \mathrm{bar}} \quad-\Delta H=\mu_{\mathrm{H} 2}=\left|p V_{\mathrm{m}}\right|$

$x \mathrm{p}^{\circ}=\frac{-\Delta H}{\mathrm{~V}_{\mathrm{m}}^{\circ}} \frac{\mathrm{T}^{\circ} \Delta S}{\Delta H}=-\frac{\mathrm{T}^{\circ} \Delta S}{\mathrm{~V}_{\mathrm{m}}^{\circ}} \Rightarrow x=-\frac{\mathrm{T}^{\circ} \Delta S}{\mathrm{p}^{\circ} \mathrm{V}_{\mathrm{m}}^{\circ}}=\Delta V_{\%} \quad \mathrm{I} \quad(\Delta S<0)$

\section{Discussion}

Equation $3 b$ expresses the volume work in the sorbent via the entropy change $\Delta S$ in the gas phase; for an ideal gas that makes evident sense. Magnesium hydride may serve for a first test; the van't Hoff reaction entropy value bases on a work of BOGDANOvić et $a l_{,}^{8}$ it is the arithmetic mean of the genuine data value and the references presented, nine in total. Densities note commonly in $\mathrm{g}_{\text {per }} \mathrm{cm}^{3}$, hence Joule is expressed in bar $\mathrm{cm}^{3}\left(0.1 \mathrm{~J}=1\right.$ bar $\left.\mathrm{cm}^{3}\right)$ and $\mathrm{V}_{\mathrm{m}}{ }^{\circ}$ given in $\mathrm{cm}^{3}$. Equation 4a shows the calculation based on material densities, ${ }^{9,10}$ equation $4 b$ those by means of thermodynamic data respective equation $3 b$.

$\Delta V_{\%}=1-\frac{\rho_{\mathrm{MgH} 2}}{\rho_{\mathrm{Mg}}}=0.1657$

$\rho_{\mathrm{Mg}}=1.738 \mathrm{~g} \mathrm{~cm}^{-3} \quad \rho_{\mathrm{MgH} 2}=1.45 \mathrm{~g} \mathrm{~cm}^{-3}$

$x=-\frac{\mathrm{T}^{\circ} \Delta S}{\mathrm{p}^{\circ} \mathrm{V}_{\mathrm{m}}^{\circ}}=\Delta V_{\%}=0.1644 \pm 0.008$

$\mathrm{T}^{\circ}=273.15 \mathrm{~K} \quad \mathrm{~V}_{\mathrm{m}}^{\circ}=22711 \mathrm{~cm}^{3} \quad \mathrm{p}^{\circ}=1 \mathrm{bar}$

$\Delta S=-136.7 \pm 6.7 \mathrm{~J}\left(\mathrm{~mol} \mathrm{H}_{2}\right)^{-1} \mathrm{~K}^{-1}=-13.67 \pm 0.67 \mathrm{bar} \mathrm{cm}^{3}\left(\mathrm{~mol} \mathrm{H}_{2}\right)^{-1} \mathrm{~K}^{-1}$

The results obtained for the plain values differ by $1 \%$ which may be called a good agreement: It is however to consider that this calculation bases on crystal densities and with regard to practical powder bed volume expansion, an according adjustment for the packing density is due. ${ }^{11}$ The investigation may 
be repeated in kind for Ti-doped $\mathrm{NaAlH}_{4}$ based on the data by BOGDANOVIC et al; ${ }^{12}$ the reactions of the system are shown in equations $5 \mathrm{a}$ to $5 \mathrm{c}$ (for the desorption reaction are $\Delta H$ and $\Delta S>0$ )

$3 \mathrm{NaAlH}_{4} \rightleftharpoons 3 \mathrm{NaH}+\mathrm{Al}+4.5 \mathrm{H}_{2}$

$\Delta H= \pm 40050 \mathrm{~J}\left(\mathrm{~mol} \mathrm{H}_{2}\right)^{-1}$ and $\Delta S= \pm 122 \mathrm{~J}\left(\mathrm{~mol} \mathrm{H}_{2}\right)^{-1} \mathrm{~K}^{-1}$

$3 \mathrm{NaAlH}_{4} \rightleftharpoons \mathrm{Na}_{3} \mathrm{AlH}_{6}+2 \mathrm{Al}+3 \mathrm{H}_{2}$

$\Delta H= \pm 36750 \mathrm{~J}\left(\mathrm{~mol} \mathrm{H}_{2}\right)^{-1}$ and $\Delta S= \pm 121 \mathrm{~J}\left(\mathrm{~mol} \mathrm{H}_{2}\right)^{-1} \mathrm{~K}^{1}$

$\mathrm{Na}_{3} \mathrm{AlH}_{6} \rightleftharpoons 3 \mathrm{NaH}+\mathrm{Al}+1.5 \mathrm{H}_{2}$

$\Delta H= \pm 46650 \mathrm{~J}\left(\mathrm{~mol} \mathrm{H}_{2}\right)^{-1}$ and $\Delta S= \pm 125 \mathrm{~J}\left(\mathrm{~mol} \mathrm{H}_{2}\right)^{-1} \mathrm{~K}^{1}$

Equation 6 shows the calculation for the relative volume change in $\mathrm{Ti}^{-N_{a A l H}}$ according to equation $5 \mathrm{a}$.

$x=-\frac{\mathrm{T}^{\circ} \Delta S}{\mathrm{p}^{\circ} \mathrm{V}_{\mathrm{m}}^{\circ}}=\Delta V_{\%}=0.1467$

$\mathrm{T}^{\circ}=273.15 \mathrm{~K} \quad \mathrm{~V}_{\mathrm{m}}^{\circ}=22711 \mathrm{~cm}^{3} \quad \mathrm{p}^{\circ}=1 \mathrm{bar}$

$\Delta S=-122 \mathrm{~J}\left(\mathrm{~mol} \mathrm{H}_{2}\right)^{-1} \mathrm{~K}^{-1}=-12.2 \mathrm{bar} \mathrm{cm}^{3}\left(\mathrm{~mol} \mathrm{H}_{2}\right)^{-1} \mathrm{~K}^{-1}$

This result of $+14.7 \%$ volume change upon hydrogenation is in concise agreement to the result of SANDROCK et al who measured for the dehydrogenation reaction $-14.7 \% .{ }^{13}$ The mono-dispersed spherical packing factor of the metal hydride bed $*$ may be identified on basis of the relevant crystal densities, ${ }^{14-16}$ as shown in equations $7 \mathrm{a}$ and $7 \mathrm{~b}$.

$1-\frac{\rho_{M H}}{* \rho_{M}}=0.1467$

$\rho_{M H}=\rho_{\mathrm{NaAlH} 4}=1.27 \mathrm{~g} \mathrm{~cm}^{-3}$

$\rho_{M}=\frac{\rho_{\mathrm{NaH}}+\rho_{\mathrm{Al}}}{2}=\frac{1.396+2.702}{2} \mathrm{~g} \mathrm{~cm}^{-3}=2.049 \mathrm{~g} \mathrm{~cm}^{-3}$

$*=-\frac{\rho_{M H}}{(0.1467-1) \rho_{M}}=0.726 \approx 0.73$

Equation $7 \mathrm{~b}$ shows the reasonable result for factor $* \approx 0.73$, close to the densest regular packing of mono-dispersed spheres $(*=0.74)$. Since related to the reaction enthalpy $\Delta S$, this approach leads further to a matter at the core of metal hydride chemistry: the question of minimum temperature and pressure necessary for complete re-hydrogenation, a critical design threshold to any metal hydride tank. This shows e.g. in the $\mathrm{Ti}^{-\mathrm{NaAlH}_{4}}$ system: for $\left[\mathrm{AlH}_{4}\right]$-formation are about 79 bar at $125{ }^{\circ} \mathrm{C}$ required, a pressure is substantially above the equilibrium pressure of about 32 bar according to equation $5 \mathrm{~b}$. These conditions are not particularly new, SANDROCK et al reported them in 2002, ${ }^{17}$ yet that formation overpotential issue was never even recognized in literature until the author clarified it's nature on basis on fundamental kinetic and thermodynamic reaction parameters. ${ }^{18}$ Thus, the problem has been already solved with general significance by approaching it from the gas phase end but the flipside effect must be recognizable for a particular sorbent as well, though rather in terms of molar volume than pressure and temperature. Towards that end, equation 6 is transformed for $p^{\circ}$ and inserted into the van't Hoff equation with subsequent transformations as shown in equations $8 \mathrm{a}$ to $8 \mathrm{~d}$. Note the argumentative switch towards desorption because in this case all negative arithmetic signs show (because $\Delta H$ and $\Delta S>0$ ).

$\mathrm{p}^{\circ}=\frac{\mathrm{T}^{\circ} \Delta S}{x \mathrm{~V}_{\mathrm{m}}^{\circ}}$

I $\Delta S=12.2 \operatorname{bar~cm}^{3}\left(\mathrm{~mol} \mathrm{H}_{2}\right)^{-1} \mathrm{~K}^{-1}$ 
$\ln \left(\frac{p_{\mathrm{eq}}}{\mathrm{p}^{\circ}}\right)=-\frac{\Delta H}{\mathrm{R} T}+\frac{\Delta S}{\mathrm{R}} \quad \mid \Delta H$ and $\Delta S>0$

$\ln \left(\frac{x \mathrm{~V}_{\mathrm{m}}^{\circ} p_{\mathrm{eq}}}{\mathrm{T}^{\circ} \Delta S}\right)=-\frac{\Delta H}{\mathrm{R} T}+\frac{\Delta S}{\mathrm{R}}$

$T\left(\Delta S-\mathrm{R} \ln \left(\frac{x \mathrm{~V}_{\mathrm{m}}^{\circ} p_{\mathrm{eq}}}{\mathrm{T}^{\circ} \Delta S}\right)\right)=\Delta H=\left|p V_{\mathrm{m}}\right|$

Equation 8d marks out the equilibrium condition; the prerequisite condition for hydrogen staying in the sorbent phase is outlined by inequality 9 : in order to prevent desorption, the temperature-entropy gain $T \Delta S$ of the reaction $(\Delta S>0)$ must be for $\mathrm{Ti}^{-\mathrm{NaAlH}_{4}}$ at least equal or smaller to the desorption enthalpy of $\Delta H=4005$ bar $\mathrm{cm}^{3}\left(\mathrm{~mol} \mathrm{H}_{2}\right)^{-1}$ as by equation $5 \mathrm{a}^{12}$ the latter being by amount identical to the $p V_{\mathrm{m}}$-energy change in the solid upon absorption.

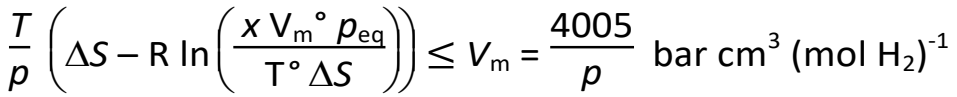

The derivative of the chemical potential with reference to pressure equals molar volume, this key intermediate in the derivation of the ideal gas chemical potential from Gibbs's fundamental equation $\mathrm{d} G$ $=V \mathrm{~d} p-\mathrm{Sd} T$ in relation to inequality 9 is shown in equation 10.

$\frac{\mathrm{d} \mu}{\mathrm{d} p}=V_{\mathrm{m}} \leq \frac{4005}{p} \operatorname{bar~} \mathrm{cm}^{3}\left(\mathrm{~mol} \mathrm{H}_{2}\right)^{-1}$

Equation 10 sketches the explanation for why a certain pressure above the equilibrium pressure can be a threshold to the hydrogenation reaction: the chemical potential of the gas phase is not sufficient for providing the $p V_{\mathrm{m}}$-energy necessary for volume expansion vital to hydride formation and allow the system to settle at the new hydride equilibrium composition. A closer investigation of this requires thus knowledge of the molar volumes respective densities of $\mathrm{NaAlH}_{4}$ and $\mathrm{Na}_{3} \mathrm{AlH}_{6}$. The former is available information; the density of $\mathrm{Na}_{3} \mathrm{AlH}_{6}$ must be assessed by the entropy method as in equations $11 \mathrm{a}$ to $11 \mathrm{c}$.

$x_{\mathrm{Na} 3 \mathrm{AlH} 6}=-\frac{\mathrm{T}^{\circ} \Delta S}{\mathrm{p}^{\circ} \mathrm{V}_{\mathrm{m}}^{\circ}}=\Delta V_{\%}=0.1503$

$\mathrm{T}^{\circ}=273.15 \mathrm{~K}$

$\mathrm{V}_{\mathrm{m}}{ }^{\circ}=22711 \mathrm{~cm}^{3}$

$p^{\circ}=1$ bar

$\Delta S=-125 \mathrm{~J}\left(\mathrm{~mol} \mathrm{H}_{2} \mathrm{~K}\right)^{-1}=-12.5 \operatorname{bar~cm}^{3}\left(\mathrm{~mol} \mathrm{H}_{2} \mathrm{~K}\right)^{-1}$

$1-\frac{\rho_{M H}}{* \rho_{M}}=0.1503 \quad \mid \quad *=0.726$

$\rho_{M}=\frac{\rho_{\mathrm{NaH}}+\rho_{\mathrm{Al}}}{2}=2.049 \mathrm{~g} \mathrm{~cm}^{-3}$

$\rho_{\mathrm{Na3AIH6}}=(-1)(0.1503-1) * \rho_{M}=1.26 \mathrm{~g} \mathrm{~cm}^{-3}$

The respective molar volumes are now determined which is shown in equations $12 \mathrm{a}$ and $12 \mathrm{~b}$. The mean molar volume of the hydride phases for the global $\mathrm{Na}-\mathrm{Al}-\mathrm{H}$ reaction is given by the weighted geometric mean because of the transient nature of $V_{m}$ during a sorption reaction, as by equation $12 \mathrm{c}$. 


$$
\begin{aligned}
& M_{\mathrm{NaAlH} 4}=54 \mathrm{~g} \mathrm{~mol}^{-1} \rho_{\mathrm{NaAlH} 4}=1.27 \mathrm{~g} \mathrm{~cm}^{-3} \Rightarrow V_{\mathrm{m}, \mathrm{NaAlH} 4}=42.52 \mathrm{~cm}^{3} \mathrm{~mol}^{-1} \\
& M_{\mathrm{Na} 3 \mathrm{AlH} 6}=102 \mathrm{~g} \mathrm{~mol}^{-1} \rho_{\mathrm{Na} 3 \mathrm{AlH} 6}=1.26 \mathrm{~g} \mathrm{~cm}^{-3} \Rightarrow V_{\mathrm{m}, \mathrm{Na} 3 \mathrm{AlH} 6}=80.95 \mathrm{~cm}^{3} \mathrm{~mol}^{-1} \\
& \bar{V}_{\mathrm{m}, \mathrm{Na}-\mathrm{Al}-\mathrm{H}}=\sqrt[3]{42.52 \cdot 42.52 \cdot 80.95} \mathrm{~cm}^{3} \mathrm{~mol}^{-1}=52.70 \mathrm{~cm}^{3} \mathrm{~mol}^{-1}
\end{aligned}
$$

Since the chemical potentials of the gas and the sorbent phase are mirror-wise coupled in an equilibrium system, any gain in chemical potential in the sorbent phase is equal to the loss of it in the gas phase: by amount, both must be equal by hydrogen equivalent as shown in equation 13 .

$$
\mu_{\mathrm{H} 2}=\mu_{M H} \quad \Rightarrow \quad\left|V_{\mathrm{m}, \mathrm{H} 2}\right|=\left|V_{\mathrm{m}, \mathrm{MH}}\right| \frac{n_{M H}}{n_{\mathrm{H} 2}}
$$

The adjustment of equation 10 to equation 13 is displayed in equation 14 which a) shows the global equilibrium reaction equation expressed for one mol of $\mathrm{NaAlH}_{4}$ with $\left.b\right) \bar{V}_{\mathrm{m}, \mathrm{Na}-\mathrm{Al}-\mathrm{H}}$ as the weighted mean molar volume of the $\mathrm{Na}-\mathrm{Al}-\mathrm{H}$ phases according to their stoichiometric proportion in the total reaction but it is c) calibrated further for obtaining the effective $\mathrm{NaAlH}_{4}$ hydrogen equivalent molar volume $\forall_{\mathrm{m} \text {, NaAlH4. }}$.

$$
\begin{aligned}
\mathrm{NaAlH}_{4} & \rightleftharpoons 1 / 3 \mathrm{Na}_{3} \mathrm{AlH}_{6}+2 / 3 \mathrm{Al}+\mathrm{H}_{2} \rightleftharpoons \mathrm{NaH}+\mathrm{Al}+1.5 \mathrm{H}_{2} \\
\forall_{\mathrm{m}, \mathrm{NaAlH} 4} & =\nabla_{\mathrm{m}, \mathrm{Na}-\mathrm{Al}-\mathrm{H}} \frac{\left.1 \mathrm{~mol} \mathrm{Na}-\mathrm{Al}-\mathrm{H} \text { [for balance with } \overline{\mathrm{m}}_{\mathrm{m}, \mathrm{Na}-\mathrm{Al}-\mathrm{H}]}\right]}{2 / 3 \mathrm{~mol} \mathrm{NaAlH} \mathrm{H}_{4}[\mathrm{MH} \text { stoichiometric weight] }} \frac{1 \mathrm{~mol} \mathrm{NaAlH}{ }_{4}[\mathrm{MH} \text { mol equivalent] }}{\left.1.5 \mathrm{~mol} \mathrm{H}_{2} \text { [total \# mol } \mathrm{H}_{2}\right]} \\
& =52.7 \mathrm{~cm}^{3}\left(\mathrm{~mol} \mathrm{H}_{2}\right)^{-1}
\end{aligned}
$$

On basis of equation 14 it is possible to sort out the conditional pressure for $\left[\mathrm{AlH}_{4}\right]$-formation as shown in equations 15 a to $15 \mathrm{c}$, leading to the result of 76 bar.

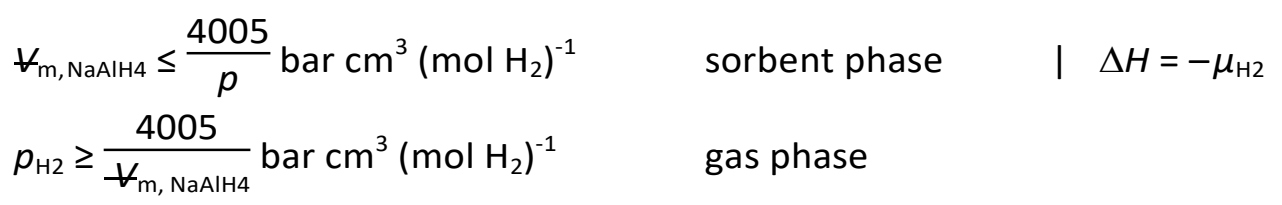

$p_{\mathrm{H} 2} \geq \frac{4005}{52.7 \mathrm{~cm}^{3}\left(\mathrm{~mol} \mathrm{H}_{2}\right)^{-1}} \operatorname{bar~} \mathrm{cm}^{3}\left(\mathrm{~mol} \mathrm{H}_{2}\right)^{-1}=76.0$ bar

The result of 76 bar in equation $15 c$ for the minimum hydrogenation pressure is in good agreement with the old empiric value of about 79 bar, ${ }^{17}$ respective the result obtained from the gas phase-centred approach of 78.7 bar, ${ }^{18}$ considering the multitude of steps necessary along the way. A final point may be made why a pressure considerably above the $\left[\mathrm{AlH}_{4}\right]$-equilibrium pressure of 32 bar at $125^{\circ} \mathrm{C}$ like e.g. 49 bar may still result in formation of $\mathrm{Na}_{3} \mathrm{AlH}_{6}$ : equation $16 \mathrm{a}$ and $16 \mathrm{~b}$ show that a pressure of 49 bar leads to a conflict with the fundamental $\left[\mathrm{AlH}_{4}\right]$-formation requirement of equation 15b.

Requirement for $\left[\mathrm{AlH}_{4}\right]$-formation: $52.7 \mathrm{~cm}^{3}\left(\mathrm{~mol} \mathrm{H}_{2}\right)^{-1} \geq \frac{4005}{p} \operatorname{bar~cm}^{3}\left(\mathrm{~mol} \mathrm{H}_{2}\right)^{-1}$

$\frac{4005}{49 \text { bar }}$ bar $\mathrm{cm}^{3}\left(\mathrm{~mol} \mathrm{H}_{2}\right)^{-1}=81.7 \mathrm{~cm}^{3}\left(\mathrm{~mol} \mathrm{H}_{2}\right)^{-1} \quad$ 々 
The molar hydrogen volume in equation 16 a represents the $\mathrm{d} \mu / \mathrm{d} p$ prerequisite to chemical potential of the gas phase for adopting the $\left[\mathrm{AlH}_{4}\right]$-equilibrium composition in the sorbent. However, a hydrogenation pressure of 49 bar does not suffice that criterion for allowing the system to settle at the new equilibrium composition. The calculation in kind for $\mathrm{Na}_{3} \mathrm{AlH}_{6}$ is shown in equation 17.

$\forall_{\mathrm{m}, \mathrm{Na} 3 \mathrm{AlH} 6}=\bar{V}_{\mathrm{m}, \mathrm{Na}-\mathrm{Al}-\mathrm{H}} \frac{1 \mathrm{~mol} \mathrm{Na}-\mathrm{Al}-\mathrm{H}}{1 / 3 \mathrm{~mol} \mathrm{Na}_{3} \mathrm{AlH}_{6}} \frac{1 \mathrm{~mol} \mathrm{Na}_{3} \mathrm{AlH}_{6}}{1.5 \mathrm{~mol} \mathrm{H}_{2}}=105.40 \mathrm{~cm}^{3}\left(\mathrm{~mol} \mathrm{H}_{2}\right)^{-1} \Rightarrow \quad p_{\mathrm{H} 2} \geq 38.0 \mathrm{bar}$

This is the complementary result to equation $16 \mathrm{~b}$ and explains why a hydrogenation pressure of 49 bar results only in formation of $\mathrm{Na}_{3} \mathrm{AlH}_{6}$. It is noteworthy that only the argumentative switch towards the gas phase allows concluding the issue eventually, while keeping focus on the sorbent phase cannot lead towards convergence in insight. This work demonstrates that approaching a reversible metal hydride problem from either end of the equilibrium system may lead to the base thermodynamic principle, eventually. However, since determining sorbent-phase thermodynamic quantities by its ideal gas phase pendant is such a fundamental principle (bespoken by the van't Hoff equation) for convergence, the gas phase vantage point is preferable, especially if a general solution is desired. For the present example of conditional $\left[\mathrm{AlH}_{4}\right]$-formation pressure, the results by the two respective approaches are with 76 bar and 78.7 bar quite close to each other, they differ on average by just 3.5\%. This is remarkable considering the ideal gas nature of the approach and that the results base on data from well-done yet different works. Considering further the manifold factors slightly affecting kinetic and thermodynamic metal hydride reaction data such as e.g. average particle size, it appears not sensible to emphasize the difference.

\section{Conclusions}

The relative volume expansion of a reversible metal hydride upon hydrogen absorption in terms of crystal densities can be determined from the van't Hoff reaction entropy and ideal gas STP parameters. This ultimately offers insight about the prerequisites to metal hydride phase formation from a material perspective, although that particular issue can be more straightforwardly and completely resolved from the system's gas-phase end.

\section{Acknowledgements}

This article originates from work done at FOTEC Forschungs- und Technologietransfer $\mathrm{GmbH}$ in Wiener Neustadt, Austria, under European Space Agency grant 4000105330/12/NL/CLP which is gratefully appreciated.

\section{Conflicts of interest}

There are no conflicts to declare.

\section{Notes and references}

1 Z. Liu, L. Xiong, J. Li, S. Liu and S. Er, Int. J. Hydrog. Energy, 2018, 43, 21441-21450.

2 F. Heubner, A. Hilger, N. Kardjilov, I. Manke, B. Kieback, Ł. Gondek, J. Banhart and L. Röntzsch, J. Power Sources, 2018, 397, $262-270$.

3 M. Sulic, M. Cai and S. Kumar, Int. J. Hydrog. Energy, 2012, 37, 15187-15195.

4 G. A. Lozano, J. M. Bellosta von Colbe, R. Bormann, T. Klassen and M. Dornheim, J. Power Sources, 2011, 196, 9254-9259.

5 S. S. Mohammadshahi, E. MacA. Gray and C. J. Webb, Int. J. Hydrog. Energy, 2016, 41, 3470-3484.

6 Y. Pang and Q. Li, Int. J. Hydrog. Energy, 2016, 41, 18072-18087.

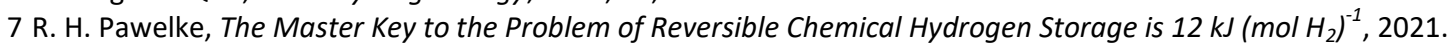

8 B. Bogdanović, K. Bohmhammel, B. Christ, A. Reiser, K. Schlichte, R. Vehlen and U. Wolf, J. Alloys Compd., 1999, 282, 84-92. 
9 RÖMPP-Redaktion and A. Hartwig, 2006.

$10 \mathrm{H}$. Sitzmann, 2006.

11 F. A. L. Dullien, Porous media: fluid transport and pore structure, Academic Press, San Diego, 2nd ed., 1992.

12 B. Bogdanović, R. A. Brand, A. Marjanović, M. Schwickardi and J. Tölle, J. Alloys Compd., 2000, 302, 36-58.

13 G. Sandrock, K. Gross, G. Thomas, C. Jensen, D. Meeker and S. Takara, J. Alloys Compd., 2002, 330-332, 696-701.

14 A. Vollmer, M. Habermeyer, RÖMPP-Redaktion, H. Sitzmann and E. Schwab, 2019.

15 H. Sitzmann, 2007.

16 RÖMPP-Redaktion, 2002.

17 G. Sandrock, K. Gross and G. Thomas, J. Alloys Compd., 2002, 339, 299-308.

18 R. H. Pawelke, On the Common Ground of Thermodynamics and Kinetics: How to Pin Down Overpotential to Reversible Metal Hydride Formation and the Complete Ideal Gas Theory of Reversible Chemical Hydrogen Storage, 2021. 